\title{
Giant 'Double Barreled' Urethrocutaneous Fistula Complicating Neonatal Circumcision - A Case Report
}

\section{Anselm Okwudili Obi, FWACS, FICS}

Department of surgery, Federal Teaching Hospital Abakaliki PMB 102 Abakaliki, Ebonyi State/Department of Surgery, Ebonyi State University, Abakaliki Ebonyi State, Nigeria. draoobi@yahoo.com

*Corresponding Author: Anselm Okwudili Obi, FWACS, FICS, Department of surgery, Federal Teaching Hospital Abakaliki PMB 102 Abakaliki, Ebonyi State/Department of Surgery, Ebonyi State University, Abakaliki Ebonyi State, Nigeria.

\section{Abstract}

Introduction: Circumcision is the commonest operation done in males worldwide. Though it is a simple procedure, it can be fraught with an array of complications ranging from the mild to the serious and rarely fatal. Urethrocutaneous fistula is one of the serious complications of circumcision but fortunately it is rare.

In this case report, we share our experience on the successful management of a large sized 'double barreled' urethrocutaneous fistula that occurred following neonatal circumcision.

Case Report: A 13 year old boy presented with large ventral sub coronal 'double barreled' urethrocutaneous fistula that resulted from neonatal circumcision by a nurse. The informant was the mother. He also had bilateral intermittent testicular pain.

The fistula measured $3.0 \mathrm{~cm}$ by $2.5 \mathrm{~cm}$ after removing the intervening skin bridge. The external urethral meatus was normally sited. Both testes were in horizontal lie. A diagnosis of post circumcision urethrocutaneous fistula and bilateral intermittent testicular torsion was made.

The patient had bilateral orchidopexy and simple repair of urethrocutaneous fistula with satisfactory outcome.

Conclusions: Urethrocutaneous fistula is an infrequent complication ofneonatal circumcision. This complication can be reduced if circumcision is carried out by trained surgeons rather than nurses.

Keywords: Penis; Circumcision; Complication; Urethrocutaneous fistula.

\section{INTRODUCTION}

Circumcision is the commonest operation done in males worldwide. It is estimated that approximately one in three males are circumcised globally [1] In the hands of trained surgeons, circumcision is supposed to be a simple and straightforward operation, however it can be fraught with a lot of complications ranging from the simple and merely cosmetic to very serious and sometimes fatal. Documented complications of circumcision include, bleeding, infection, excessive removal of the foreskin, redundant foreskin, skin bridges, epidermal inclusion cyst, buried penis, iatrogenic hypospadias, urethrocutaneous fistula, partial glans amputation, complete glans amputation and death [2-4]. The overall complication rate for circumcision ranges from 0.2 to $5 \%$ [5]. Urethrocutaneous fistula (UCF) is one of the serious complications of circumcision [2-6], but fortunately it is extremely rare [6, 7]. They may be single $[2,5]$ or multiple[6, 8]. Reported sizes of UCF complicating circumcision vary considerably. Appiah et al. [2], documented 56 UCF ranging in size from pin hole defects $(<5 \mathrm{~mm})$ to large defects $(>10 \mathrm{~mm})$. We encountered a case of huge 'double barreled' urethrocutaneous fistula complicating neonatal circumcision. It measured $3.0 \mathrm{~cm}$ by $2.5 \mathrm{~cm}$ after removing the intervening skin bridge. This is perhaps the largest post circumcision UCF to be reported to date. Its successful treatment is discussed with a brief literature review. 


\section{CASE REPORT}

A 13 year boy presented to us with history of splaying of urine from the ventral aspect of the penile shaft during micturition. The history dated back to the neonatal period. The informant was the mother. He had been circumcised in the neonatal period by a nurse and this problem was noticed a few days after the circumcision. The patient also complained of intermittent bilateral testicular pain of recent onset.

On examination, the penis had a normal well sited external urethral meatus. The ventral surface had a sub coronal urethrocutaneous fistula with intervening Skin Bridge creating a 'double barreled' appearance (Fig $1 \mathrm{~A}$ ). The defect measured $3.0 \mathrm{~cm}$ by $2.5 \mathrm{~cm}$ after removing the skin bridge (Fig 1B). He also had bilateral horizontal lie of the testes. We made a diagnosis of post circumcision urethrocutaneous fistula and bilateral intermittent torsion of the testes.

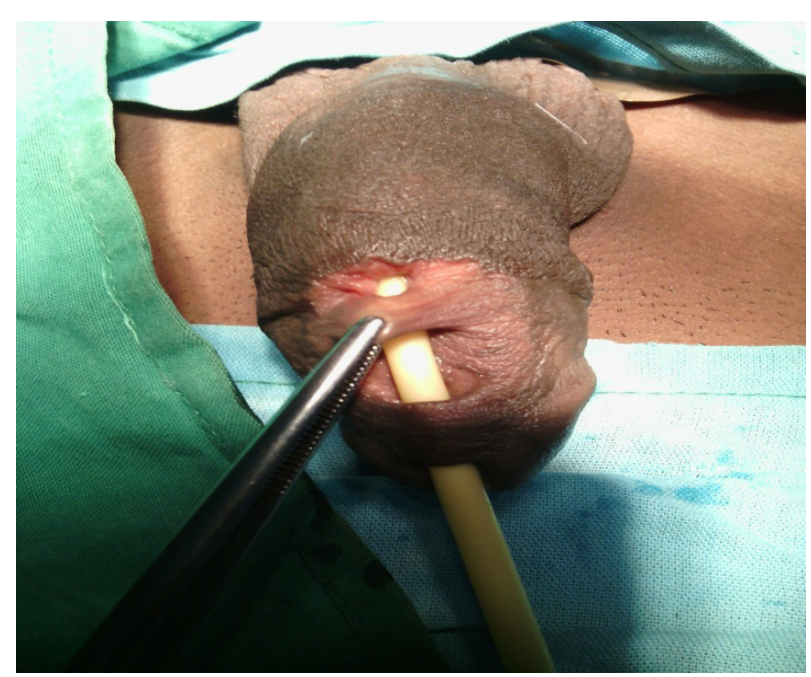

Fig 1A. Large 'double barreled' urethrocutaneous fistula.

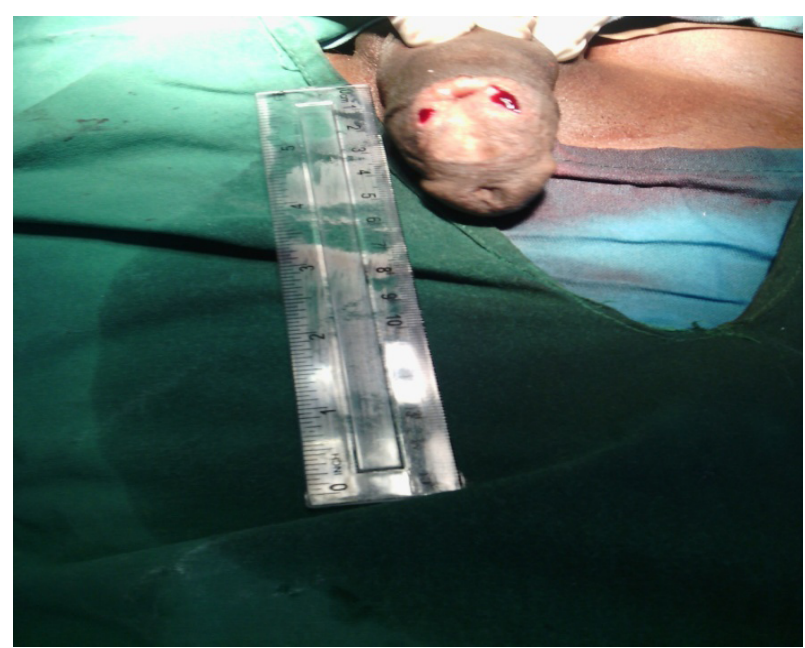

Fig 1B. Fistula after excision of skin bridge
He had a HB of $11.6 \mathrm{~g} / \mathrm{dl}$. Urinalysis, urine microscopy culture and sensitivity $(\mathrm{m} / \mathrm{c} / \mathrm{s})$, random blood sugar and retroviral screening tests were normal.

\section{MANAGEMENT}

The patient had urethroplasty and bilateral orchidopexy under general anesthesia. The urethrocutaneous fistula was repaired by simple closure technique. The repair was done in 4 layers with $4 / 0$ polyglactin suture. The intervening skin bridge was first excised to create a single urethrocutaneous fistula (Fig 1B). Then the urethral plate was delineated and separated from the surrounding skin with a circumcising incision. The urethral plate was closed by sub epithelial running suture over a size $12 \mathrm{~F}$ catheter. The suture line was covered by 2 layers of dartos fascia, followed by skin closure.

Patient received I.V cefuroxime injection $750 \mathrm{mg}$ and I.V metronidazole $250 \mathrm{mg}, 15$ minutes before surgery. Post operatively he received I.V cefuroxime injection $375 \mathrm{mg} 12 \mathrm{hrly}$ and I.V metronidazole $250 \mathrm{mg}$ 8hrly for 48 hours. These were converted to oral medication after 48hours. He was discharged home on the fifth post operative day for follow up in the clinic. The urethral stenting catheter was removed on the $14^{\text {th }}$ post operative day.

The follow up period was characterized by wound infection and recurrent urethrocutaneous fistula. The recurrent urethrocutaneous fistula was pin hole sized (Fig 1D). It was managed conservatively with culture specific antibiotics and wound dressing. The fistula closed spontaneously after 8 weeks. He had good urinary stream. He has been followed up for 2 years without event.

\section{Discussion}

The incidence of circumcision complications ranges from $1 \%$ to $15 \%$ [9]. Urethrocutaneous fistula (UCF) is an uncommon but serious complication of circumcision $[2,6,7]$. They may be single or multiple $[2,5,6,8]$. The incidence rate of UCF complicating circumcision ranges from $0 \%$ to $21 \%[3,10,11]$. A single centre study reported a very high rate of up to $77.8 \%$ [2]. Overall there are few reported cases in literature $[2,7]$. The aetiology is believed to be related to crushing injury to the urethra with a haemostat while attempting to ligate a bleeding frenular artery during circumcision. The urethra may also be caught in heavy suture passed for the same purpose and later slough off or there may be direct inadvertent scalpel laceration of the urethra while trying to excise the frenular portion of the prepuce $[2,5,6]$. The injury usually reveals itself in the immediate post operative 
period by dribbling of urine from the undersurface of the penis during micturition. The location is usually coronal or sub coronal.

Surgical correction of urethrocutaneous fistula of any aetiology can be challenging. Several methods have been described in the literature. The choice of technique depends on the proximity of the fistula to the glans, the skill of the surgeon and availability of local tissues suitable for repair. Penile fasciocutaneous flaps can be raised from the ventral or dorsal surface of the penis to cover the urethral defect $[5,12,13]$ or a simple (primary) closure technique can be used [4, $8,14]$. If the fistula is distant from the glans, primary closure may be considered when the urethral lumen is not narrowed [5]. If the fistula is close to the glans it may be converted to a hypospadias by splitting the glans and repairing with any of the distal hypospadias repair techniques $[5,15]$. A Mathieu style skin flap advancement with repeat glanuloplasty around the advanced flap [5] or an onlay island flap from the dorsal or ventral penile skin may be used to bridge the urethral defect [12].

Multiple urethrocutaneous fistulae pose a slightly different challenge. Sancaktutar et al [5] described a case of multiple circumferential urethrocutaneous fistula that required penile degloving to fully identify the fistulae openings. He observed four fistulae that combined to form two openings that were closed primarily. Also Agrawal et al [8] described a complex post circumcision multiple urethrocutaneous fistula; 3 in number that combined to form a single fistula that required a resection and anastomosis to treat. Our index case was a 'double barreled' or 2 in 1 fistula (Fig 1A). We converted this to a single fistula by excising the intervening skin bridge (Fig 1B) and then closed primarily (Fig 1C).

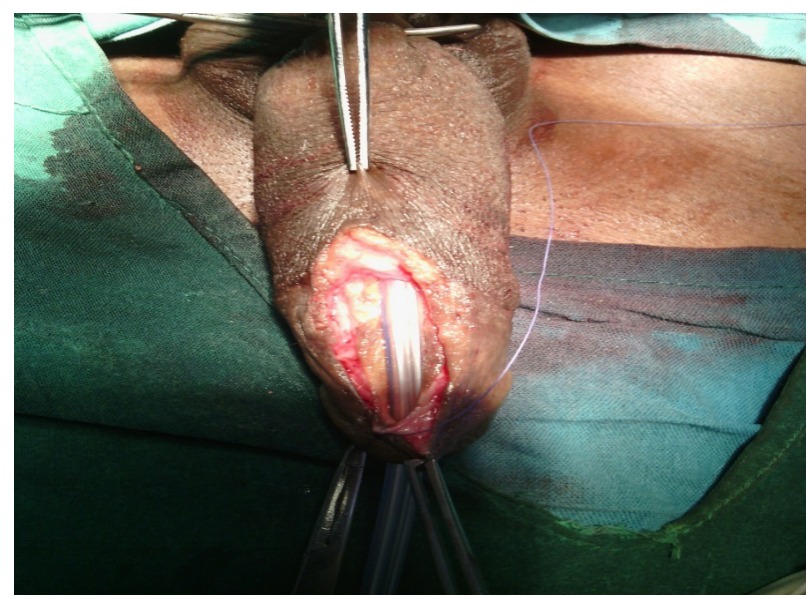

Fig 1C. Simple repair of fistula with running suture of 4/0 polyglactin after a circumcising incision.

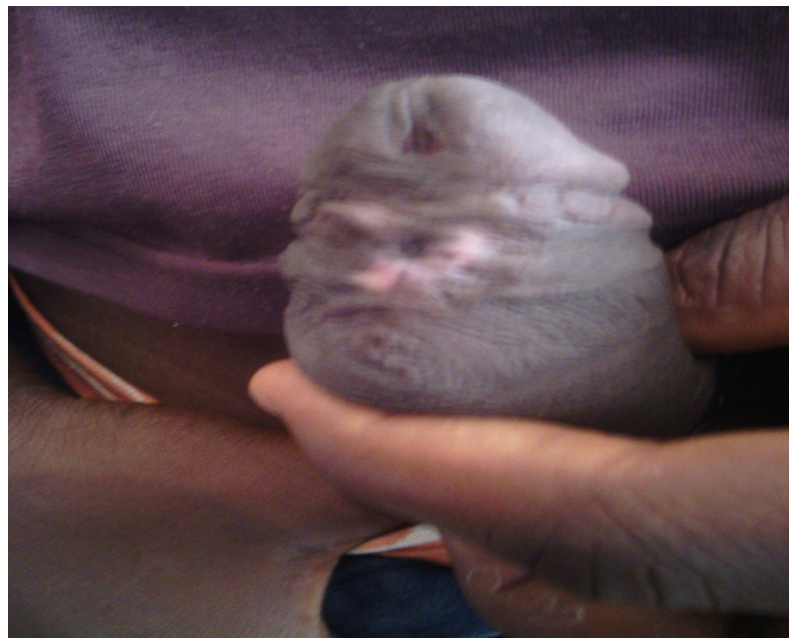

Fig 1D. Post operative picture showing recurrent pin hole sized urethrocutaneous fistula which closed spontaneously after 8 weeks.

Our index case was closed with a primary closure technique because there was adequate urethral tissue for the repair. Whatever method is used adequate dartos fascia cover is important as it prevents overlapping of epithelial suture lines and is key to preventing re-fistulation. A stent may be placed for a week or more [5]. Repair of urethrocutaneous fistula may be complicated by recurrent fistula despite adhering to sound surgical principles especially if the initial fistula was very large [15]. This may require secondary procedures [15] or be managed conservatively as was done in our index case. The final outcome of repair is usually good in experienced hands.

Severe complications of circumcision such as UCF can be reduced to the barest minimum if circumcision is carried out by trained surgeons because studies have shown that there is a higher incidence of complications with nurses and traditional circumcisers [10, 16]. Also extreme caution is required when attempting to control bleeding from the frenular artery because the urethra is very superficial in this position.

\section{ConCLUSIONS}

Urethrocutaneous fistula is an infrequent complication of neonatal circumcision. This complication can be reduced if circumcision is carried out by trained surgeons rather than nurses. Care should be exercised to avoid this complication because of its severe morbidity and high cost of repair. Successful repair is possible in experienced hands. 
Giant 'Double Barreled' Urethrocutaneous Fistula Complicating Neonatal Circumcision - A Case Report

\section{REFERENCES}

[1] WHO/UNAIDS. Male Circumcision: Global Trends and Determinants of Prevalence, Safety and Acceptability. Geneva: World Health Organization; 2008.

[2] Appiah AAK , Gyasi-Sarpong KC, Azorliade $\mathrm{R}$, Aboah K, Laryea OD, Otu-Boateng $\mathrm{K}$ et al. Circumcision-related tragedies seen in children at the Komfo Anokye Teaching Hospital, Kumasi, Ghana. BMC Urology 2016; 16:65 DOI 10.1186/ s12894-016-0183-1

[3] Mogotlane SM, Ntlangulela JT, Ogunbanjo BGA. Mortality and morbidity among traditionally circumcised Xhosa boys in the Eastern Cape Province, South Africa. Curationis [Internet]. 2004 Sep 28 [cited 2014 Nov 9];27(2). Available from: http://www.curationis.org.za/index.php/ curationis/article/view/980

[4] Ceylan K, Burhan K, Yilmaz Y, Can S, Kus, A, Mustafa G. Severe complications of circumcision: an analysis of 48 cases. J Pediatr Urol.2007;3:32-35.

[5] Sancaktutar AA, Pembegül N, Bozkurt Y, Kolcu $B$, and Tepeler A. Multiple Circumferential Urethrocutaneous Fistulae as a Rare Complication of Circumcision and Review of Literature. Urology 2011;77: 728-729.

[6] Baskin LS, Canning DA, Snyder HM and Duckett JW.: Treating complications of circumcision. Pediatr. Emerg. Care 1996; 12: 62-68

[7] Baskin LS, Canning DA, Snyder HM 3rd, Duckett JW Jr. Surgical repair of urethral circumcision injuries. J Urol. 1997; 158: 2269-2271.
[8] Agrawal A, Parelkar S, Shah H, Sanghvi B, Joshi M, Mishra P. Multiple circumferential urethrocutaneous fistulae: a rare complication of circumcision. J Pediatr Urol. 2009; 5: 240-242.

[9] Harrison NW, Eshelman JL, Ngugi PM. Ethical issues in the developing world. Br J Urol. 1995;76: 93-96.

[10] Okeke LI, Asinobi AA, Ikuerowo OS. Epidemiology of complications of male circumcision in Ibadan, Nigeria. BMC Urol. 2006; 6(1):21.

[11] Osifo OD, Oriaifo IA. Circumcision mishaps in Nigerian children. Ann Afr Med. 2009; 8(4):266-70.

[12] Baskin LS, Duckett, JW, Ueoka K, Seibold J and Snyder HM 3rd. Changing concepts of hypospadias curvature lead to more onlay island flap procedures. J Urol. 1994; 151(1): 191-196.

[13] Obi AO. Traumatic Urethrocutaneous fistula. Case report and literature review. Afr J. Urology 2013;19: 198-201.

[14] El-Bahnasawy MS, El-Sherbiny MT. Paediatric penile trauma. BJU Int. 2002;90: 92-96.

[15] Ikuerowo SO, Bioku MJ, Omisanjo OA, Esho JO. Urethrocutaneous fistula complicating circumcision in children. Niger J Clin Pract 2014;17:145-8

[16] Weiss HA, Larke N, Halperin D, Schenker I. Complications of circumcision in male neonates, infants and children: a systematic review. BMC Urol. 2010; 16:10-12.

Citation: Anselm Okwudili Obi, FWACS, FICS. Giant 'Double Barreled'Urethrocutaneous Fistula Complicating Neonatal Circumcision - A Case Report. Archives of Urology. 2018; 1(2): 1-4.

Copyright: (C) 2018 Anselm Okwudili Obi, FWACS, FICS. This is an open access article distributed under the Creative Commons Attribution License, which permits unrestricted use, distribution, and reproduction in any medium, provided the original work is properly cited. 